\title{
Facilitating Adoption of International Information Infrastructures: A Living Labs Approach
}

\author{
Bram Klievink $^{1}$ and Inge Lucassen ${ }^{2}$ \\ ${ }^{1}$ Delft University of Technology, Delft, The Netherlands \\ a.j.klievink@tudelft.nl \\ ${ }^{2}$ TNO Netherlands Organisation for Applied Scientific Research, Delft, The Netherlands \\ inge.lucassen@tno.nl
}

\begin{abstract}
One of the key challenges that governments face in supervising international supply chains is the need for improving the quality of data accompanying the logistics flow. In many supply chains, individual parties in the chain work with low quality data for their operations and compliance, even though somewhere in the supply chain, better data is available. In the European CASSANDRA project, ICT-supported information infrastructures are developed to exchange data between businesses and government, to support visibility on the supply chain and the re-use of information. However, to gain better data, actors need to be open about their operations, processes and systems to parties that are geographically and culturally on the other side of the world. This adds (perceived) vulnerabilities for parties already operating in a highly competitive environment. This could be a major barrier for making the innovation work. We argue that Living Labs, as a collaborative innovation approach, are able to support the adoption of innovative information infrastructures. They help identifying gains that innovations may bring. Furthermore, the trust-based setting also mitigates the added (perceived) vulnerability such innovations bring for the participants. We illustrate this by examples from the CASSANDRA Living Labs.
\end{abstract}

Keywords: Data quality, supply chains, public-private information infrastructures, living labs.

\section{Introduction}

The main topics in government supervision of today's international trade are efficiency and security. Outsourcing, consolidating cargo and multi-modal transport chains have complicated the organisation and optimisation of logistics and have put additional challenges to managing information and data in these logistics chains. In addition, the information system in international logistics is much influenced by its own legacy, and as a result, documents that originating from the $19^{\text {th }}$ century are still being used. Results of these complications can easily be found: carriers and importers are being asked to make legal declarations about goods they have never seen, 
documents that contain crucial information can lag three days behind the goods, and these documents contain information that obscure the true values, such as the identity of the real seller or buyer. These issues have a common solution: supply chain visibility, where data can be shared between business and government, providing end-to-end visibility for all stakeholders, where information can be provided by the originating party and re-used by others. This should result in a significant reduction of transaction costs while it also improves the information quality when advanced mechanisms are used for data capture and cross checking data from various sources. However, this can only be realised when government inspection agencies and the business community work together.

With the advancement of technology innovations it becomes possible to improve the information exchange worldwide, by creating electronic connections between organisations [1]. Data can be made available digitally and is instantaneously available to supply chain partners, and authorities around the globe. However, a wide range of complexities arises. Gathering, sharing and combining information from various sources requires the development of information exchange platforms that are used by a wide variety of stakeholders having diverse interests [2]. Both business systems and digital government infrastructures are connected to each other, owned and operated by a diverse set of public and private actors. The technical complexities of implementing these platforms is compounded by the number of stakeholders affected by and involved in the decision making process. For such a platform to work in the dynamic context of international trade and logistics, the system needs to be flexible, heterogeneous, interoperable, and above all entirely secure. The use of such platforms also introduces new complexity and new uncertainties for the parties involved, due to increased interdependence and potential vulnerability [3, 4]. Ultimately, this requires the collaboration of many different stakeholders that will have to make a strategic decision on the willingness and necessary investments for sharing information about their processes, products, etc. A perceived increase in vulnerability due to this kind of innovation may hinder industry uptake.

In this paper, we present the experiences from the Living Labs (LL) approach used in the CASSANDRA project. The LLs fosters collaboration between the parties in a small group community for a specific supply chain. As a result, this group, operating in a neutral Living Labs setting, is able to build inter-organisational trust that allows the various parties to assess their supply chain from an end-to-end perspective and openly discuss activities, logistics processes, information processing and production, data requirements and how this may be disclosed to others. Consequently, benefits or business cases may be realised that go far beyond the initial quest for better data and move towards more sophisticated use of the electronic links that are formed between parties [5]. We show how the Living Labs enable parties to find these more sophisticated uses by creating a trusted setting that counters the added vulnerability that is introduced by adopting an information exchange platform to electronically connect to partners in the supply chain [3]. 


\section{Background: Data Exchange Infrastructures and IOS Adoption Concepts}

\subsection{Data Exchange Infrastructures in International Trade}

The research and development project that we focus on in this paper aims to improve efficiency, security and compliance in international trade and logistics by integrating information flows on goods, actors, (commercial) contracts and logistics (e.g. transportation). Both the businesses in the supply chain and supervision authorities gain enhanced visibility benefits based on better quality information, in terms of accuracy, timeliness and completeness [2]. This is even more so if enhanced data quality is combined with innovative information integration and visibility, tracking and scanning technologies and linked to operational risk management [1]. In addition to addressing supply chain inefficiencies, businesses can employ this high quality information to facilitate compliance.

This innovation requires the business community to consider the supply chain from end-to-end, with special attention for data quality and the processes from where the data originates. This is the concept of 'data from the source'. Depending on the configuration of a specific supply chain and who is executing which activity, different parties may be best equipped to provide certain data elements that can be re-used by other parties as well. For example, a purchaser of goods knows which goods were ordered, in what quantity and for what value. But a logistics service provider that performs container stuffing may be actually matching the order with the container manifest, thus providing better quality data on the shipment and the contents of the container, which is then the basis for other logistic activities and many (legal) documents along the chain.

To enable the wide variety of actors in the supply chain to share data amongst businesses and between the business community and government agencies, ICT infrastructural facilities need to be developed. Hanseth et al. [6] depict these infrastructures as information infrastructures to emphasize a more holistic, socio-technical and evolutionary perspective to place the growth in the combined social and technical complexity at the centre of an empirical scrutiny [7]. Realising these infrastructure requires transformations, i.e. meaning radical changes in core processes within and across organisational boundaries [8-11]. Organisations that have implemented information integration solutions have reported significant benefits that support the IT/IS evolution process [12].

The European CASSANDRA project proposes a solution for an innovative information infrastructure for international trade, called the data pipeline. It is a concept based on the use of Service-Oriented Architectures (SOA) to enable access to the existing information systems that are used and operated by the various parties in global supply chains $[2,13]$. It is a virtual bus, created by linking ERPs, existing inter-organisational trade and logistics platforms connecting e.g. port and business community platforms, and systems for tracking, tracing and monitoring the goods [13]. The data pipeline provides one integrated access point to the different sets of information that already exist, but are currently fragmented throughout the supply chain. 
However, to set the right requirements for a data-sharing platform, the parties literally need to sit together to share and assess the end-to-end supply chain and data availability and quality, e.g. does the data originate from a standardized and verifiable process; was it made available by manual entry, or automatically from an ERP system? Due to competitive pressure, these parties normally do not discuss this as part of their normal day-to-day operations. As a result, any ICT innovation to improve endto-end supply chain visibility has a high risk of failure due to focusing primarily on improving data sharing techniques and standards, without making an in-depth assessment of the best data quality sources in each individual supply chain and the challenges in gaining mutual trust and cooperation.

\subsection{Inter-organisational Relationships in IOS}

The data pipeline can be considered an inter-organisational information system (IOS), as information crosses the boundaries of individual parties and data and (potentially) functionality is being shared between organisations [14]. Most early literature considered a lead party (or 'sponsor') of an IOS, which has an important role in defining its functionality, the participants and funding structure of the system [14]. However, given the complexity in international trade and logistics, all parties (and thus potential 'sponsors') also depend on supply chain partners to realise the expected or intended benefits by introducing, supporting or otherwise sponsoring the system. Therefore, the adoption of an IOS, and the factors influencing adoption, is a key research topic $[15,16]$.

In studying the factors that influence the adoption of Electronic Data Interchange (EDI) as a form of IOS, Chwelos et al. [16] seek for factors at three levels; the technology, the organisation and the inter-organisational level. In the findings of their empirical research, there are two parts that stand out in determining the intention to adopt an IOS; the external pressure and the readiness. The external pressure consists of both competitive pressures and enacted pressure from the trading partners. The readiness concerns the financial resources and the IT sophistication, including management support, which a party needs to adopt an IOS. As due to its nature an IOS only works if other partners also use the system, trading partner readiness was also found to be of importance.

The contemporary field of information or digital infrastructures, which can be considered a direct successor to the IOS studies, puts more emphasis on the interorganisational aspect. They focus on the role that socio and political factors play in enacting, adopting and supporting information infrastructures [17]. Here, information infrastructures are seen as an open, heterogeneous, evolving and IT facilitated sociotechnical system that is shared between multiple actors [18].

In their 1997 paper, Hart and Saunders emphasise that IOS innovations lead to new complexity and primarily new vulnerabilities for organisations that adopt an IOS through the increased interdependence [3]. They take the existing relationship between parties as the starting point for their reflection. The way in which innovation impacts the existing relationship and the way in which parties treat each other in the innovation, determines the extend of the potential future benefits of the innovation. 


\subsection{Building Trust for Depth of Use of the Innovation}

The three main elements of Hart and Saunders' thesis are power, trust and vulnerability. They argue that although pressure can be used to stimulate adoption of an IOS, this can also negatively impact the relationships between parties. This is because the perceived vulnerability of the partners increases. An IOS enables information to cross the boundaries of the organisation [3]. Trust, in this context, means that parties need to be confident that their partners do not misuse the information they gain in the IOS, nor exploit the increased vulnerability. If trust is built, there is a tendency to continue the collaboration. Hence trust and continuity are mutually reinforcing. Ultimately, this is important in order to gain the maximum benefits of the IOS as the innovation often starts with only a small transaction set, often with a limited number of parties. Based on the work of Massetti, Hart and Saunders [3] argue that there are various characteristics to the use of an IOS:

- Breadth of use, i.e. the number of IOS partners;

- The diversity of the transaction/document set;

- The volume of transactions via the IOS;

- Depth of use, i.e. first just electronic document transfer, deeper use is interorganisational application to application transfer, next is interconnected or shared databases and ultimately up to coupled or shared (automated) work environments.

The more the IOS is used in depth, the greater the vulnerability of the parties opening-up to each other. Furthermore, Hart and Saunders argue that most parties start with simple exchange of documents, and at the time of adoption of the IOS do not yet foresee to what extend the IOS will impact their future operations and collaboration. The expectation is that more benefits can be gained if the integration is more in depth. The principle that trust and continuity is mutually reinforcing is reflected in this gradual implementation of IOS.

In this paper, we argue that a Living Lab research and development approach can help in facilitating a safe environment and facilitate building inter-organisational trust, which enables parties to design, implement, adopt and evaluate the use of an IOS. The Living Lab setting especially enables commercial partners to move beyond arms-length trading relationships and collaborate more to discover shared benefits of introducing the IOS.

\subsection{Trust and the Living Labs Approach}

Hart and Saunders use the classification of Mishra [19] to identify four dimensions of trust in the context of sharing information in an IOS:

- Competence: partner is able to process information properly and efficiently;

- Openness to innovation;

- Care: no misuse of new interdependence and vulnerabilities; and

- Reliability, i.e. actors do as they say. 
In this paper, we state that a Living Labs approach is not only a valuable research and development tool to put innovative information infrastructures to practice, but also creates a setting that facilitates trust, which is what we focus on. It enables the various actors to gain confidence that the innovation can indeed help in realizing mutual benefits, and that the partners will not act opportunistically and misuse the vulnerability.

A Living Lab is defined as a "gathering of public-private partnerships in which businesses, researchers, authorities, and citizens work together for the creation, validation, and test of new services, business ideas, markets, and technologies in real-life contexts" [20]. Continuity, openness and empowerment of the actors are three of the key principles that Bergvall-Kåreborn et al. [20] identified with respect to Living Labs. A returning aspect of Living Labs is the crucial, and high level of collaboration, enabling to build inter-organisational trust [21]. Limited trust and collaboration will inevitably result in sub-optimized designs and solutions, no commercially valuable resulting services and no valid proof of concept. Innovation through Living Labs is therefore only possible when partners aim for collaborative innovation.

With respect to governance of choice for new solutions, it is crucial that Living Labs are open and neutral with respect to technology or business models. This is needed to get the most out of a collaborative innovation process, "by avoiding the problem of path dependency \& lock-in and at the same time optimizing interaction among organizations" [22]. Consequently, Niitamo et al. [22] argue that a Living Lab needs to bring access to state-of-the-art technology, which is diverse, i.e. not just one technology, but competing technologies that are delivered through different business models. Hence, on the technology side, cooperation with (and between) technology vendors is necessary, including both SMEs and larger firms [22]. When asking investments of these directly competing companies in creating innovative products, creating an environment of trust, cooperation and willingness to teach and learn together, is also one of the crucial factors of success and first points of attention when setting up a Living Lab.

Compared to other test and experimentation platforms, e.g. prototyping platforms, testbeds, field trials, market pilots and societal, Living Labs have a higher level of design focus [22]. In Living Labs more efforts are being put on the design phase, resulting in less commercial maturity at inception, but on the other hand, the end solution should better fit the requirements of the users and therefor have higher chances of success in the long run. Because of all complexities, it is evident that the goal of the Living Lab study needs to be clear and equally understood by all participants at the start of the project. If this is not the case, it will become increasingly difficult to create an environment of trust and end up with having the right focus and commitment of the individual partners, that each have their importance and contribution.

\section{The Living Labs Approach}

Within the Living Labs of the CASSANDRA project, actors from business and government cooperate to develop and evaluate new ICT solutions that support 
international trade, logistics and compliance in a real-life pilot setting. These partnerships are facilitated by the research environment, where partners from academia and other research institutions provide a "neutral ground" for the interactions, aiming to initiate and facilitate processes of consensus building, networking and policy making.

\subsection{Select Demonstration Trade Lanes}

First step in setting up the Living Labs was the identification of suitable trade lanes. A trade lane was defined as a single lane from origin to destination, from a specific seller to a specific buyer, across fixed transport modes. These trade lanes were selected with the business partners based on flow and process stability, and relationship with the trade lane partners. After selection of the trade lanes, the next step was to assign a dedicated IT solution provider to the trade lane. This was important as it also made the solutions that would be tested in a trade lane more specific. Choice for a solution provider was driven by various factors such as estimated maturity of IT in the trade lane, specific requirements by business partners on the trade lane, geographical presence and the need to end with a set of demonstrations that would have enough variety to support scientific research and a good basis for calculating the final results in the overall evaluation of the CASSANDRA solutions, including an extrapolation to the industry at large of logistics, international trade and compliance. The closed user groups, or trade lane teams, took form.

\subsection{Creating Mutual Understanding}

The next step to work on a common level of understanding, which in case of CASSANDRA included getting acquainted on a personal level, understand each other's businesses and interests and the detailed processes and products. This was established in a workshop with local trade lane partners to get a first mapping of the trade lane's parties, processes, IT implementations, etc. This was done in working sessions where process mappings, dossier analysis and interviews were performed. Coming to the necessary level of understanding in the CASSANDRA project was a challenge for the partners that are less acquainted with the supply chain processes as the principle of getting data from the best or even original source means that a detailed knowledge of processes, resulting information exchange, and data control mechanisms is needed.

In this stage, the team got a first common understanding and importantly a common mission is finding answers to the unanswered questions. Much of these answers were found in team trips to the other ends of the trade lane (i.e. Asian countries). Here, supply chain parties were visited, interviewed, possible solutions discussed, etc. In many cases, earlier assumptions, sometimes with $99 \%$ security upfront, turned out to be incorrect. Parties that have been working closely for many years, never got to talking about such details. There was an open and collaborative attitude towards the supply chain partners. Meetings never resulted in a closed attitude from either side, but almost without exception in open and animated discussions. In many cases, the group expanded with experts from the partners (literally on the other side of the 
world), bringing their expertise and dynamic to the team. Working in a Living Lab setting opened up possibilities to discuss operations openly. As a result, businesses learned more about the way their partners operate and the sources of the data they worked with in a day than they have done in years of collaboration before.

In the next chapter, we describe findings from the recent Living Labs, making it at this stage not possible to assess whether relationships lasted or if IT solutions reached commercialisation.

\section{Findings from the CASSANDRA Living Labs}

Within the CASSANDRA project, there are three Living Labs that share a common end vision, solution providers and project partners, but also each one has its own specific user group, regional characteristics, level of IT maturity and stakeholder community. In terms of building inter-organisation trust, this gives additional complications as a larger group of partners, that not only bring specific expertise but also different backgrounds, need to collaborate and agree on a final solution. Therefore, it was agreed upfront that local implementations of the solution might differ according to the needs of local stakeholders. To detail the overall vision and simultaneously start Living Labs from a bottom-up approach brings an additional complication in realising and aligning project and Living Lab goals. Coordination of these two levels needs to be a joint effort of a dedicated smaller group of people that can continuously monitor development and targets and that clearly steers and communicates. As this also transforms the way government agencies operate, and digital government infrastructures are part of the overall information infrastructures, government needs to be involved from the beginning.

Due to the project schedule, various trade lane options were selected and a lack of understanding existed on the potential benefits for the various supply chain parties that were asked for support. The trade lanes where this problem did not occur, had the advantage that these were already used in earlier research projects, or there was involvement of strategic, long term partners and customers of the consortium members.

\subsection{Building Trust through Open Collaboration}

Within the trade lane teams it was easier to build a high level of trust and collaboration since most partners in the logistics chain are already acquainted over several tiers and the project provided them with a neutral discussion platform. It might have been beneficial that the coordinating partner in most of the trade lanes was a neutral knowledge institute. Involving solution providers in the various trade lanes, already in the first stages, also supported trust. First, because the team worked jointly on a common understanding of trade, logistics, compliance and possible solution. Second, because there were only a limited number of external parties, being the solution providers, that needed to get acquainted with the trade lane and the more or less confidential data related to it. Third, the solution providers in the trade lane were 
chosen as such that there were not competing but cooperating. This also stimulates knowledge sharing between solution providers.

\subsection{Trusted Setting Enables Depth of Understanding and Potential Use}

Defining the information requirements of the various stakeholders and designing the solution is less of a challenge, provided that the partners have got acquainted and all have the same understanding of the processes, the problems to be solved and the possible solutions. This is complicated by practicalities from the international character of the topic. Supply chain parties sometimes know each other only by name, are affected by complex relationships due to the different levels of contracting in international logistics, and have no ability to meet face-to-face regularly to know each other well enough to be convinced of mutual understanding. Furthermore, having a common and complete understanding of end-to-end supply chains means that all parties need to understand both the physical and administrative processes of shipping goods around the globe. This includes not only the business side of these processes, but also compliance processes, interests of inspection authorities, and the systems that support these processes and potentially offer relevant solutions.

The exercises that contributed to this common understanding have proven to be of great importance. First, it showed a project partner, that was working closely for several years with an overseas party, jointly developing new logistics services, was completely unaware of the existence of an IT system that holds all the forwarding information. This system only came to the team's attention after a day of discussion at the forwarder's premises in Asia. The system proved to be essential for data capture in the project. Sharing this data, instead of the information they exchanged before, enabled the project partner to significantly improve their operations, including warehouse planning, and enhance their service level to their customer.

Second, the trips overseas also brought more understanding of logistics processes for the partnering authorities. Existing control mechanisms in supply chains, such as the use of a tallyman during container stuffing, can be a crucial indicator of a supply chain being in control. Information about these control mechanisms can support compliance and risk management.

Getting a common understanding of the trade lane required the whole team to be able to work on various levels of detail at the same time, understanding each other's detailed processes and products without losing the bigger picture and effects on the final solution. A Living Lab approach requires a certain set of skills and competences, both analytical and social, for its participants as well as the coordinator. The role of the coordinator in these sessions is to bring the participants together on a social level but also on a content level. The coordinator therefore needs to have basic understanding of the various perspectives and being able to work as a translator and moderator in discussions. When a Living Lab includes a public-private partnership, this is another dimension to the standard complexity. It is essential to formulate the constraints and incentives imposed by authorities to keep the discussions focused and within their legal frame. This is important to steer the project's efforts in a direction which results in not only a technically viable solution but also a solution that fits in current policy, and as such is acceptable and accessible for the market after the project ends. 
Managing a public-private partnership in Living Lab innovation requires both public and private parties to reach a certain level of understanding and trust which is much influences by the power relation that naturally exists.

\subsection{Supporting Depth of Use Creates Bigger Advantages}

In the example mentioned earlier, the Living Labs setting enabled the business community in the trade lane to identify better sources of data. This is partly a result from the collaborative approach, as the Asian owner of the information system did not know what the use their partners on the other side of the world could have for their data. At the same time, being able to connect this data source to the interorganisational data sharing system was also a result from the trust-basis created in the Living Lab setting. The information system owner got in-depth information on the way the information would be used, and what the supply-chain-wide benefits could be. For them, this mitigated the perceived risk that the information would be used opportunistically. They saw how it could instead strengthen their existing relationship with their European partner. Sharing the information through the IOS enabled them to increase the information exchange and the efficiency of the supply chain as a whole, instead of optimising the individual steps that any single party could control.

The careful assessment of where data comes from, and the finding that this party could provide information from primary records, also enables benefits from compliance and governmental inspection perspectives. As the customs organisation got a better understanding of the source of the data and of the way that the business community themselves asserted its correctness (i.e. data from the source, combined with a tallyman), they are able to assess the security of this supply chain as a whole. This may result in a decrease of the inspection burden that was caused by incomplete or inaccurate information at import.

\section{Conclusion and Discussion}

The development of information exchange infrastructures for international trade and logistics is a complex undertaking. Much of the data that is important can come from multiple sources and is often altered, inaccurate and sometimes intentionally vague. To gain better data on global goods flows and thereby enhance the visibility on those flows in an inter-organisational information system or IOS, just interconnecting systems is insufficient. The stakeholders need to provide detailed requirements and specifications for such a system, meaning that knowledge is needed on the source of the data, the processes in other organisations that produce the data, existing control mechanisms and the various IT systems. With this, they are able to assess the quality level that is needed for each data element on what point in time, and of the quality level that each partner and system can provide. .

Aspects that can influence innovative developments in this area are external pressure, readiness and the trust and relationship between partners. The more the IOS is used in depth, the greater the vulnerability of the parties that are opening-up to each 
other and the higher the need for mutual trust. This already starts in the specification phase, where discussion requires openness on operations, processes and systems to parties that could geographically and culturally be on the other side of the world. Parties might perceive to be vulnerable when opening up, especially since they are operating in a highly competitive environment. Living Labs offer the possibility to create a safe environment in which parties can create sufficient mutual understanding and trust to perform the crucial first steps in specifying the requirements for an IOS. The idea that trust and continuity are mutually reinforcing also reflects the crucial success of these first steps in a gradual implementation of IOS. Therefore, we argue that the small user group innovation in Living Labs are not just a good instrument to get this done in a research setting, but also to support the eventual adoption of the information infrastructures and support the required transformation. Such a collaborative innovation approach gives the ultimate adoption a boost by focusing not just on the benefits that parties can gain from the innovation, but also respects and deals with the added (perceived) vulnerability that such innovations bring for the participants.

The examples from the CASSANDRA Living Labs show that working in dedicated teams can work really well in creating an open and safe environment. The lessons learnt show that a specific, shared and well-understood objective for the cooperation is crucial for selecting the team and also final success. Working jointly on a common understanding of the trade lane and the stakeholder's needs not only brings knowledge but also improves the relationship and team spirit. The people working in the team need a certain set of competences and skills in order to create this positive atmosphere and work effectively. Also, the role of the neutral coordinator is important to moderate the discussions and to facilitate mutual understanding with necessary functional translations. The common understanding is the crucial starting point for developing a common roadmap to implement an IOS for a group of organisations.

Acknowledgements. This paper results from the CASSANDRA project, which is supported by funding from the 7th Framework Programme of the European Commission (FP7; SEC-2010.3.2-1) under grant agreement no. 261795. Ideas and opinions expressed by the authors do not necessarily represent those of all partners of the project.

\section{References}

1. Tan, Y.-H., et al. (eds.): Accelerating Global Supply Chains with IT-Innovation. ITAIDE Tools and Methods. Springer, Berlin (2011)

2. Klievink, B., et al.: Enhancing Visibility in International Supply Chains: The Data Pipeline Concept. International Journal of Electronic Government Research 8(4) (2012)

3. Hart, P., Saunders, C.: Power and trust: Critical factors in the adoption and use of electronic data interchange. Organization Science 8(1), 23-42 (1997)

4. Kumar, K., Van Dissel, H.G.: Sustainable collaboration: managing conflict and cooperation in interorganizational systems. MIS Quarterly 20(3), 279-300 (1996)

5. Massetti, B., Zmud, R.W.: Measuring the extent of EDI usage in complex organizations: strategies and illustrative examples. MIS Quarterly 20(3), 331-345 (1996) 
6. Hanseth, O., Monteiro, E., Hatling, M.: Developing information infrastructure: The tension between standardization and flexibility. Science, Technology \& Human Values 21(4), 407-426 (1996)

7. Henningson, S., Henriksen, H.Z.: Inscription of behaviour and flexible interpretation in Information Infrastructures: The case of European e-Customs. Journal of Strategic Information Systems 20(4), 355-372 (2011)

8. Murphy, J.: Beyond e-government the world's most successful technology-enabled transformations, executive summary, INSEAD the business school for the world, pp. 1-124 (2005)

9. Weerakkody, V., Dhillon, G.: Moving from E-Government to T-Government: A Study of Process Re-engineering Challenges in a UK Local Authority Perspective. International Journal of Electronic Government Research 4(4), 1-16 (2008)

10. Kim, H., Pan, G., Pan, S.: Managing IT-enabled transformation in the public sector: A case study on e-government in South Korea. Government Information Quarterly 24, 338-352 (2007)

11. Weerakkody, V., Janssen, M., Dwivedi, Y.K.: Transformational Change and Business Process Reengineering (BPR): Lessons from the British and Dutch Public Sector. Government Information Quarterly 28(3), 320-328 (2011)

12. Irani, Z., Love, P.E.D.: Developing a frame of reference for ex-ante IT/IS investment evaluation. European Journal of Information Systems 11(1), 74-82 (2002)

13. Overbeek, S., et al.: A Web-Based Data Pipeline for Compliance in International Trade. In: WITNESS 2011: Delft, The Netherlands (2011)

14. Vitale, M.R., Johnson, H.: Creating competitive advantage with interorganizational information systems. MIS Quarterly 12(2), 152-165 (1988)

15. Robey, D., Im, G., Wareham, J.D.: Theoretical Foundations of Empirical Research on Interorganizational Systems: Assessing Past Contributions and Guiding Future Directions. Journal of the Association for Information Systems 9(9), 497-518 (2008)

16. Chwelos, P., Benbasat, I., Dexter, A.S.: Research report: empirical test of an EDI adoption model. Information Systems Research 12(3), 304-321 (2001)

17. Tilson, D., Lyytinen, K., Sørensen, C.: Digital Infrastructures: The Missing IS Research Agenda. Information Systems Research 21(4), 748-759 (2010)

18. Hanseth, O., Lyytinen, K.: Design theory for dynamic complexity in information infrastructures: the case of building internet. Journal of Information Technology 25, 1-19 (2010)

19. Mishra, A.K.: Organizational responses to crisis: The centrality of trust. In: Kramer, R.M., Tyler, T. (eds.) Trust In Organizations, pp. 261-287. Sage, Newbury Park (1996)

20. Bergvall-Kåreborn, B., Holst, M., Ståhlbröst, A.: Concept Design with a Living Lab Approach. In: 42nd Hawaii International Conference on System Sciences, HICSS (2009)

21. Pavlou, P.A.: Institution-based trust in interorganizational exchange relationships: the role of online B2B marketplaces on trust formation. Journal of Strategic Information Systems 11, 215-243 (2002)

22. Niitamo, V.-P., et al.: State-of-the-art and good practice in the field of living labs. In: Proceedings of the 12th International Conference on Concurrent Enterprising: Innovative Products and Services through Collaborative Networks. Milan, Italy (2006) 